\title{
A lousa de uso escolar: traços da história de uma tecnologia da escola moderna
}

\section{The slate in the scholar use: traces of a modern school technology history}

\author{
Valdeniza Maria Lopes da Barra ${ }^{1}$
}

\begin{abstract}
RESUMO
O trabalho que segue é fruto de um estudo que se inscreve no universo da cultura material escolar, sendo a metodologia empregada a de natureza bibliográfica, com vistas a destacar a história de um suporte técnico-material de relevância das práticas escolares da escola moderna, a lousa de uso escolar. Concentra-se no espaço temporal dado pelo século XIX, por ser este o cenário que dará visibilidade ao esforço de difusão das primeiras práticas escolares de ensino. Parte da hipótese de que a relação entre material e método pode traduzir concepções de ensino, conferindo centralidade à lousa como a tecnologia que, inscrita no conjunto das práticas escolares, resultará na constituição e consolidação do modelo escolar da transmissão simultânea de ensino.
\end{abstract}

Palavras-chave: pedra; lousa; quadro-negro; ensino simultâneo.

\begin{abstract}
The following paper is the product of a study that inscribes itself in the universe of the material school culture, having as methodology the bibliographical method, aiming to highlight the history of a technical material support that is relevant for the practices of the modern school: the scholar slate. We concentrate in the time and space given by the nineteenth century, since it is the scene that will give visibility to the effort of diffusion of the first school practices of teaching. We start from the hypothesis that the relation between material and method can translate teaching conceptions, conferring centrality to the slate as the technology that, when inscribed in

${ }^{1}$ Universidade Federal de Goiás (UFG). Faculdade de Educação. R. 235 (Delenda Rezende de Melo) s/n. Setor Universitário. Goiânia, Goiás, Brasil. CEP: 74605-050.
\end{abstract}


the set of school practices, will result in the constitution and consolidation of the scholar model of simultaneous transmission of education.

Keywords: rock; slate; blackboard; simultaneous education.

O itinerário da produção da sala de aula como célula básica do espaço escolar moderno se constitui no engendramento dos processos que envolvem a difusão da leitura e escrita entre as classes populares, a instituição da escola pública e a necessidade de produzir um modo de organização do ensino traduzido na utensilagem material básica requerida para o ofício do ensinar e aprender a ler, escrever e fazer contas.

Os exercícios que marcam o início da aprendizagem

da escrita, todos os mestres sabem, são laboriosos. Até que a atenção seja fixada, que o olho tenha aprendido a ver e a mão a traçar, quantas páginas, quantos cadernos desaparecem cobertos de horrorosos rabiscos e mais cheios de manchas de tinta que de linhas de escrita! (BROUARD, 1911a, p. 109).

E. Brouard (1911a) fala de um material de uso escolar, a ardósia. Conhecida como "pedra", "laje" ou "lousa", a ardósia surgiu numa época em que se queria ensinar aos pobres e, pode-se acrescentar, coincidiu com a chegada dos "meninos" à escola. A utilização de materiais como o papel ou a pena de ganso era inviável do ponto de vista econômico; o preparo da pena exigia habilidade e era tarefa do professor. Quanto ao papel, "é caro, gasta-se depressa e suja-se muito; alem d'isto exige uma mesa e um arsenal de acessorios, tinteiro, penna, regoa, lapis" (ARDÓSIA, 1886). Com a utilização das ardósias, as "crianças das escólas infantis podem facilmente encostal-as aos joelhos e não correm o inconveniente de chegar em casa com a roupa e os dedos cheios de tinta" (ARDÓSIA, 1886).

A provável origem etimológica da palavra "ardósia" seria correlata do seu emprego arquitetônico na "Irlanda, numa localidade chamada Ardy, portanto do nome celta ard, pedra", ter-se-ia "formado este de ardósia" (BOSC, 1879, p. 145). Era usada na construção de igrejas anteriores ao século VI; os romanos a usavam na construção de paredes. Pequenas, as "pedras de ardósia formavam espécies de mosaicos que rompiam a monotonia das paredes" (p. 145), revestiam banheiros e urinóis, decoravam coberturas e fachadas na França da Idade Média. A arquitetura estabelecia que uma boa ardósia deveria ser homogênea, dura, de cor escura e lisa, não absorver água, ser perfeitamente plana, de densidade uni- 
forme e se deixar cortar sem que se quebre (p. 145). A ardósia no estado natural podia ser chamada "rocha folhada" (VIOLLET-LE-DUC, 1876, p. 453). Em contato com o ar, endurece; em contato com a água, emite um cheiro argiloso. Pode ser encontrada em diferentes cores: marrom-vermelho escuro, cinza claro, verde, azul escuro ou violeta (BOSC, 1879, p. 145-147).

Ainda segundo Bosc (1879, p. 146), a ardósia de uso arquitetônico era encontrada em cinco tipos de "modelo inglês" e cinco de "modelo francês". No "modelo inglês", as medidas de comprimento variavam entre o mínimo de 0,217 m e o máximo de $0,325 \mathrm{~m}$; a largura, entre o mínimo de 0,160 m e o máximo de $0,222 \mathrm{~m}$; a espessura ficava entre o mínimo de 2,5-3 mm e o máximo de $4 \mathrm{~cm}$; o peso ia do mínimo de $0,258 \mathrm{~kg}$ ao máximo de $0,550 \mathrm{~kg}$. Já o "modelo inglês" apresentava medidas maiores: o comprimento variava entre o mínimo $0,54 \mathrm{~m}$ e o máximo de $0,64 \mathrm{~m}$; a largura mínima era de $0,27 \mathrm{~m}$ e a máxima, de $0,36 \mathrm{~m}$; a espessura era de 5,5-6 mm (medida igual para todas); e o peso oscilava entre $2,448 \mathrm{~kg}$ e $3,868 \mathrm{~kg}$.

O emprego da ardósia em atividades de escrita é anterior ao seu emprego escolar: no século XIV, pequenas ardósias podiam ser usadas como uma espécie de registro de bolso (LAROUSSE, 1933, p. 564-565).

Pestallozzi teria sido o responsável pela introdução do emprego escolar da ardósia nas escolas primárias da Suíça (GIOLITTO, 1986, p. 281). Os diretores das escolas mútuas teriam preconizado e difundido o emprego escolar da ardósia. Seu uso sucedeu ao das caixas de areia no debuxo de letras ${ }^{2}$ e daria lugar mais tarde ao papel e à pena (DEFODON, 1911).

As escolas mútuas surgiram na Inglaterra no final do século XVIII. Foram seus mentores Joseph Lancaster e André Bell ${ }^{3}$. No método de ensino mútuo, o "agente principal" seria o monitor escolhido entre os "alunos da classe que se distinguisse em relação aos demais" (CARDOSO, 1999, p. 120-121). Os alunos mais adiantados eram previamente preparados pelo professor para ensinar aos demais. Tratava-se do "princípio da reciprocidade de ensino entre os alunos", daí a denominação ensino "mútuo" (HAMEL, 1818 apud GRÉARD, 1911, p. 1998). Os monitores eram os "estudantes mais adiantados" e também podiam ser denominados "decuriões”, cada um responsável por uma das “decúrias (ou

2 "Debuxos" eram os exercícios que treinavam os movimentos da mão e desenvolviam habilidade manual para o traço das letras e algarismos. Tais exercícios constituíam-se de riscos, rabiscos ou desenhos.

3 André Bell era médico e pastor anglicano. Joseph Lancaster pertencia à seita dos quacres. Existem controvérsias sobre a autoria do método de ensino mútuo, se de Bell ou de Lancaster: segundo Cardoso (1999, p. 120), Bell teria utilizado o método nas Índias Inglesas nos anos de 1787 e 1794 (e publicou sua experiência em 1797); Lancaster, em Londres, numa escola gratuita, criada em 1798 e destinada a 800 meninos e 300 meninas pobres. 
docúrias), isto é, grupos de dez alunos" (FERNANDES, 1999, p. 32). Entretanto, uma decúria poderia ter mais ou menos de dez alunos. Lancaster $(1823$, p. 19) previu um decurião para cada grupo de vinte "meninos" da classe de aprender o alfabeto; "se há dobrado, são precisos dous decuriões; e assim na proporção de cada vinte".

O emprego da areia nas atividades de escrita teria sido introduzido por André Bell, que, em passagem pela Índia, teria presenciado “crianças hindus que estudavam sob a direção de um de seus camaradas e escreviam com os dedos sobre a areia" (DEMKÉS, 1911, p. 185). Para Lancaster (1823 p. 20), a areia deveria ser colocada sobre a mesa, em um espaço "pintado de preto", para que, quando os "meninos" fizessem "as lêtras na arêa branca, o chão preto" mostrasse "a figura". A areia seria de uso restrito aos alunos integrantes da primeira classe. Estes alunos teriam 4 ou 5 anos de idade e aprenderiam as letras segundo as "três ordens conforme a similaridade da sua forma":

[...] huma linha; v. g. as letras I, H, T, L, E, F, i, r. [...] formação de um ângulo; como A, V, M, N, Z, R, Y, X, _ , k, y, x, z. [...] hum circulo ou uma curva; como O, U, C, J, G, D, P, B, R, Q, S, _ a, o, b, d, p, q, g, e, $\mathrm{m}, \mathrm{n}, \mathrm{h}, \mathrm{t}, \mathrm{u}, \mathrm{r}, \mathrm{fs}, \mathrm{f}, \mathrm{j}[\ldots]$. A maior dificuldade em ensinar as letras ocorre naquellas cuja forma he quasi similhante, e se distinguem unicamente pela mudança de posição: p, q, b, d (LANCASTER, 1823, p. 21).

O decurião diria o nome da letra e os outros "meninos" escreveriam com os dedos sobre a areia. O "menino" capaz de "escrever e distinguir" as letras deveria sentar perto daquele que ainda não o soubesse, de sorte que este pudesse "copiar a forma das letras, vendo o outro fazellas". Terminado o exercício da escrita, os meninos "descançaráõ até que a arêa seja alisada pelo decurião com um bornidor, tal como se usa para bornir a roupa, ou de páo de similhante forma". O alisamento da areia eliminaria os traços. Para ser alisada com rapidez e perfeição, a areia deveria estar "bem sêcca". Um "bornidor" era usado pelo decurião para alisar a areia de cada um dos alunos da classe. Isso gerava alguns problemas para o controle dos alunos que ficavam à espera do alisamento da areia. A solução para este problema era a substituição do "bornidor" por "huma taboa liza que faz o mesmo effeito, e previne que se tome emprestado sem licença para bornir a sua propria roupa, ficando desta sorte a classe sem ter o que fazer, por falta de ferro" (LANCASTER, 1823, p. 78).

As ardósias destinadas ao uso escolar aparecem de duas maneiras: naturais ou artificiais. As naturais se parecem com aquelas usadas na arquitetura, guar- 
dadas as especificidades do emprego escolar, a escrita. São "pequenas placas escolhidas entre placas mais ou menos regulares, têm a superfície lisa. Cortadas regularmente e aplainadas nas bordas, um lápis também em ardósia permite marcar nela traços suficientemente visíveis" (BROUARD, 1911a, p. 109).

Até a década de 70 do século XIX, não havia na França a "proscrição absoluta" nem o "emprego universal" da ardósia escolar. A preocupação da escola francesa era "transformar a ardósia ou melhor substituí-la por uma superfície ardosiada, uma ardósia artificial" (BROUARD, 1911a, p. 110). Esta teria a finalidade de suprir os inconvenientes da natural - "difícil de carregar, fria, frágil, dura" -, somando-se aos inconvenientes do lápis de ardósia, que "por sua vez é muito duro, e muito quebradiço, tornando-se logo um fragmento sobre o qual os dedos se irritam" (BROUARD, 1911a, p. 110). Segundo Campagne (ARDÓSIA, 1886), a ardósia artificial poderia se apresentar sob a forma de "uma lamina de folha de ferro esmaltada" ou de "uma folha de cartão coberta por uma massa delgada de madeira pintada de preto" - ou seja, um pequeno quadro-negro. Para o uso da lousa artificial, é necessário "um lápis de massa menos dura que não faz a mão pesada, e que se póde metter n'uma lapiseira ordinaria" (ARDÓSIA, 1886).

Uma das grandes vantagens da ardósia natural era o baixo custo. Os inconvenientes revelados pelo uso que dela se fazia eram reduzidos graças a alguns aperfeiçoamentos, tais como a fixação de ardósias sobre a superfície das mesas e a colocação das ardósias em quadros de madeira, o que as tornava portáteis e menos frágeis. O uso escolar da ardósia revela inconvenientes: afinal é dura, pesada e fria; e o "lápis" pesa e irrita os dedos pequenos das crianças. Criam-se novas formas de aperfeiçoamento da ardósia: fixação na mesa, enquadramento de madeira. Persistem inconvenientes de uso, introduz-se o quadro-negro, uma prancha de madeira de dimensões maiores suportada por cavaletes, regulável por tarraxas na altura e inclinação da prancha, de superfície pintada de cor escura, para ser usada com giz, um material com mobilidade, isto é, portátil.

É provável que o quadro-negro tenha sido uma criação dos Irmãos das Escolas Cristãs, ordem religiosa fundada pelo padre Jean Baptiste de La Salle ${ }^{4}$. La Salle foi o responsável pela instituição do método de ensino simultâneo. O

4 Jean Baptiste de La Salle nasceu em Reims, em 30 de abril de 1651, e morreu em 7 de abril de 1719. Fundou o Instituto dos Irmãos das Escolas Cristãs. Defendia a instrução gratuita para crianças pobres, órfãos e outros pobres que precisavam trabalhar e não podiam estudar. Teve conflitos com as corporações de mestres-escrivães, porque propunha a vulgarização da escrita. Conduta das escolas cristãs é a sua obra de maior destaque, dividida em duas partes. Foi impressa pela primeira vez em Avignon, no ano de 1720 (BUISSON, 1911, p. 1.514-1.523). O sumário desta obra comporta, de fato, cinco divisões: a entrada na escola e o início das aulas; desjejum e almoço (em que se fala pouco de comer e muito de oração); as lições; a escrita; e a aritmética. A primeira 
quadro-negro é uma ardósia artificial, versão transformada da ardósia natural. É difícil precisar a data de sua invenção. No Dictionaire de pédagogie, o quadro-negro surge com a revisão do conceito de simultaneidade feita pelos Irmãos das Escolas Cristãs, em 1811 (BROUARD, 1911b, p. 2787-2789). Guión (1998, p. 260) apresenta o Método prático de leitura, de François de Neufchâteau, ministro do interior na França do ano VII da Revolução (1798); tal método propõe o "ensino simultâneo da leitura e da escrita", com a determinação de que a "aprendizagem está baseada na imitação: o menino reproduziria sobre sua 'ardósia' os caracteres desenhados pelo professor no quadro-negro".

Com base nos registros examinados, o quadro-negro teria surgido entre o final do século XVIII e o início do século XIX. Em ambos os registros, é um instrumento de ensino coletivo, que aparece vinculado à simultaneidade do ensino de ler e escrever. É material escolar que marca o método de ensino de transmissão simultânea e divide espaço, tempo e exercícios com a ardósia de uso individual. Inventado pelos irmãos lassaleanos, o quadro-negro seria rapidamente absorvido por outras práticas de ensino, como as de ensino mútuo.

O quadro-negro não consta do manual do método de ensino mútuo que foi traduzido do "original inglez" para o português por Guilherme Skinner em 1823. Esta obra, intitulada Systema Britanico de Educação: sendo hum completo Tratado de melhoramentos e invenções praticadas por Josè Lancaster, tinha como finalidade a "illustração das Academias e Aulas do reino Unido de Portugal, Brasil e Algarve, tanto paras Meninos como para Meninas" (LANCASTER, 1823, folha de rosto). Neste manual, é previsto o emprego de mesas de areia para os alunos iniciantes, e de lousas e papel para os mais adiantados, na execução de lições de escrita e de aritmética. Além destes materiais, este manual apresenta um "novo methodo de ensinar o Alfabeto", que se caracteriza pela existência de um material coletivo: trata-se de "hum papelão suspenso n'algum prégo na parede da aula" (LANCASTER, 1823, p. 22); o alfabeto estaria registrado neste papelão e deveria ser posto diante da primeira classe de meninos disposta em semicírculo. Defodon (1911) informa que, para La Salle, a necessidade de um material escolar de caráter coletivo é expressão da transição do ensino individual para o ensino simultâneo e da instituição de um material escolar que garantisse maior rapidez no ensino da leitura: substituía ao ensino individual "o ensino simultaneo, ao quadros por conseguinte tomavam o lugar do livro" (DEFODON, 1911, p. 3). Segundo Campagne (1886, p. 363), "o uso de cartas de grandes dimensões, destinadas a serem penduradas (cartas muraes) para poderem ser vistas de longe, era já conhecido na antigüidade; mas

parte da obra era "Os exercícios que se fazem nas escolas cristãs e a maneira como se devem fazer"; a segunda, "Os meios para estabelecer e manter a boa ordem" (MANACORDA, 1997, p. 228). 
só neste século é que começaram a ser introduzidas nas escolas". A carta mural era um quadro com a lição de leitura impressa, recurso material proposto por $\mathrm{La}$ Salle, cujo caráter coletivo possibilitava a superação do ensino individual pela instituição da intervenção simultânea do ensino. Este tipo de material coletivo possibilitava maior rapidez na aprendizagem inicial da leitura. E não era só isto. Até então, o princípio da simultaneidade era expresso pela prescrição de que os alunos tivessem "livros semelhantes" para que pudessem "ter a mesma lição" (CAMPAGNE, 1886, p. 636). Sendo o livro um material de alto custo e tendo La Salle a preocupação com a vulgarização da instrução elementar para as classes populares, a substituição do livro por quadros impressos com as lições de leitura não apenas marca a importância do material na instituição do método de ensino, como confere ao caráter coletivo do material escolar as propriedades da racionalidade dos procedimentos metodológicos de ensino e revela o cunho social do método. O manual do ensino mútuo (LANCASTER, 1823) manifesta preocupações parecidas. Em vez do "methodo ordinario", no qual "cada menino deve ter um livro", é proposto "hum methodo de ensinar a lêr e escrever, pelo qual hum livro servirá em lugar de seiscentos".

Para effetuar isto será bom que este livro seja impresso n'hum typo tres vezes maior que o commum. Neste livro cada pagina seria impressa n'huma folha, e cada huma das suas folhas se pregaria n'hum papelão ou taboa, suspensa por huma corda na parede da sala ou n'outro qualquer lugar conveniente: hum destes papelões ou taboas conteria o alfabeto; os outros, palavras ou syllabas de duas até seis letras. As lições de lêr vão subindo desde palavras de seis ou mais (LANCASTER, 1823, p. 29).

A propriedade coletiva do papelão, "taboa" ou carta tinha implicações sobre o modo de organização dos "meninos", refletidas no cuidado com a visibilidade do material segundo o conjunto da classe:

[...] doze até vinte meninos estaráõ n'hum semi-circulo diante de cada carta, de sorte que elles possão distinguir o que está impresso, para lêr ou soletrar tão bem como como se elles tivessem cada hum o seu livro na mão contendo aquillo mesmo [...] e quando estes meninos tenhão repetido toda a lição tantas vezes quantos forem os meninos neste circulo, estes irão para seus lugares soletrarem escrevendo na lousa (LANCASTER, 1823, p. 30). 
A questão econômica era apresentada como um dos princípios do método de ensino mútuo proposto por Lancaster (1823, p. 30): "Se o valor e importância deste plano, por poupar papel e livros para ensinar a lêr e a soletrar, se não fizer recommendavel por si, então todo o meu trabalho tem sido inutil".

O papelão viria a ser substituído pelo quadro-negro, material escolar que, entre outras propriedades, sintetizava a necessidade de um instrumento coletivo que seria usado para uma classe de alunos com níveis de adiantamento semelhantes. Tanto no método de ensino simultâneo quanto no de ensino mútuo, o modo de organização escolar era feito em classes. Segundo o manual do método de ensino mútuo, haveria "oito classes daquelles que aprendem a lêr", oito "classes daquelles que aprendem a escrever" e doze "classes para aprender Arithmetica" (LANCASTER, 1823, p. 15-16). O número de "estudantes" de cada classe seria definido pelo "talento" de cada um: quando o professor verificasse que o "talento" de um grupo de "estudantes" fosse "quasi igual no que aprendem", procederia de modo a agrupar todos "na mesma classe"; assim, "qualquer numero de estudantes pode formar huma classe, sem limite a hum numero determinado" (LANCASTER, 1823, p. 13). Antes de empregar o quadro-negro, a prescrição para o ensino "extemporaneo" de aritmética numa escola organizada pelos princípios de Lancaster determinava que, para cada classe, se ensinaria uma operação, e cada operação estaria impressa num papelão.

A cada classe pertencerá huma conta conforme a regra que estão. Esta conta está impressa em huma carta ou papelão. Os oito meninos estarão ao redor da conta que elles devem fazer; e a carta ou papelão, em que ella se acha, estará pendurada na parede (LANCASTER, 1823, p. 40-41).

A criação do quadro-negro marcaria o vínculo entre método (ensino simultâneo) e material (quadro-negro). Entretanto, a relação entre material e método deve ser matizada, especialmente quando se verifica a rapidez com que se deu a apropriação deste material escolar pelas práticas do método de ensino mútuo. Foram realizados diferentes estudos sobre a difusão deste método de ensino nas escolas elementares das primeiras décadas do século XIX da França (LESAGE, 1999), do Rio de Janeiro (CARDOSO, 1999), de São Paulo (HILSDORF, 1999; BARRA, 2001) e de Minas Gerais (FARIA FILHO; ROSA, 1999)5. Nos estudos

${ }^{5}$ Estes estudos estão reunidos na obra organizada por Maria Helena Câmara Bastos e Luciano Mendes de Faria Filho, A instrução elementar do século XIX: o método monitorial/mútuo (FARIA FILHO; BASTOS, 1999). Nesta obra, há ainda estudos sobre a difusão do método de ensino mútuo 
realizados por estes autores, o quadro-negro aparece como um material entre outros, isto é, do ponto de vista prescritivo, o quadro-negro é material escolar absorvido pelo método de ensino mútuo. Desta constatação deve-se registrar que os três estudos que tratam da escola elementar brasileira contemplam o período das décadas de 20 a 40. O trabalho de Fernandes (1999) sobre o ensino mútuo em Portugal no início do século XIX deve ser destacado, uma vez que neste estudo os materiais escolares relacionados são cartas, tábuas, ardósias, penas de pedra e outros. A ausência do quadro-negro na escola mútua portuguesa é condizente com a ausência do quadro-negro na obra de Lancaster, traduzida por Guilherme Skinner em 1823 na cidade do Porto. A referência ao quadro-negro nas escolas brasileiras de instrução elementar aparece entre o final da década de 20 e o começo dos anos 30 do século XIX - e, deve ser acrescentado, nas escolas que tinham a prescrição de empregar o método de ensino mútuo.

Em muitos lugares, "os procedimentos do ensino simultâneo, ao substituir aqueles do modo mútuo, diminuem a utilidade das ardósias na maior parte das classes, com exceção da mais elementar: o quadro-negro e os cadernos instalavam-se com vantagem" (BROUARD, 1911a, p. 110). A necessidade de um material coletivo dá lugar ao quadro-negro em vez da "carta", e o quadro-negro torna-se "indispensável tanto ao ensino simultâneo como ao ensino mútuo" (GIOLITTO, 1986, p. 275). Assim, o quadro-negro estará entre os materiais escolares recomendáveis para o método de ensino mútuo ou simultâneo, transitando entre uma ou outra prática de ensino. A dissociação entre o quadro-negro e a instituição do método de ensino simultâneo corresponde ao reconhecimento do uso deste material tanto numa modalidade de ensino quanto em outra, mas, em ambas, constata-se que o quadro-negro se associará ao ensino de aritmética, ao passo que o ensino de ler e escrever teria como suportes privilegiados os impressos: cartas, cartazes e traslados.

Existem diferentes maneiras de evidenciar o emprego das lousas e do quadro-negro nas práticas escolares.

Em práticas que fossem orientadas pelos preceitos de Lancaster (1823), o emprego da lousa era privilegiado no ensino simultâneo de ler e escrever. Com o "methodo de soletrar escrevendo na lousa, une[m-se] o soletrar e o escrever, esta é a base do adiantamento em lêr" (p. 180). E o autor prossegue: "adotar um plano que promova a ordem e regularidade nas aulas para adiantar o progresso dos alunos em lêr; por isso recommenda-se a introducção do novo methodo de soletrar nas lousas" (p. 80). 
Apesar da afirmação de Brouard (1911a), o quadro-negro não suplantaria o emprego da lousa individual. Ambos os materiais seriam recomendados nas práticas de ler e escrever, especialmente nas classes iniciantes, durante todo o século XIX. Nas classes mais adiantadas, nas quais as lousas fossem substituídas por cadernos, as ardósias pareciam sair da mesa (horizontal) dos alunos para formar o quadro-negro (vertical, mosaico sem marcas), que, suportado por cavaletes ou pendurado na parede, redesenhava a disposição espacial da aula, redefinindo os lugares dos agentes e dos materiais escolares. Tratava-se de uma inovação material escolar importante: mais que resultado, era processo da constituição de uma forma de instrução que se fizesse eficiente no ensino de crianças pobres.

Mantendo-se ou não a ardósia individual dos alunos, a presença do quadro-negro redefine a disposição espacial da aula. Material coletivo de uso privilegiado do professor, o quadro-negro indica a todos da classe a lição que deve ser executada. O olhar vertical do aluno é dirigido pelo plano horizontal da lousa individual, enquanto o plano vertical do quadro-negro dá a direção horizontal do seu olhar. Há uma redefinição espacial da aula, do mobiliário escolar, especialmente dos bancos e das bancas (mesas), dos agentes e das relações de ensino. Defodon (1911) registra que o emprego do quadro-negro possibilita a "lição direta":

A lição do mestre consistirá em escrever, sobre o quadro-negro, não antes da aula, mas na presença dos alunos, as partes das letras, as palavras, a frase sobre as quais os alunos deverão exercitar e que terão de reproduzir sobre suas ardósias ou sobre os seus cadernos. E não lhe bastará dar o exercício por escrito, explicá-lo-á; dirá por que o escolheu, dirá como se deve fazer para o imitar (DEFODON, 1911, p. 2-3).

A importância do quadro-negro é expressa por Hébrard (1995):

Os frades das escolas cristãs inventaram um instrumento do qual ainda não deixamos de nos servir: o quadro-negro. Esta superfície mal pintada, sobre a qual, com um pedaço de calcário fácil de conseguir na mineração das adjacências, o aluno é capaz de traçar letras ou números, é duradoura porque pode ser apagada. É o suporte privilegiado do exercício quando este se torna uma prática não mais dos colégios elitistas, mas das escolas destinadas à instrução de todas as crianças (HÉBRARD, 1995, p. 6). 
A organização das práticas escolares da instrução elementar requer dispositivos que garantam disciplina, ao mesmo tempo em que ensinem:

O mestre hábil principia cedo o ensino de escrever, pois que, sabendo o menino escrever, tudo vai prestes, e logo sobrevem bom emtendimento de orthografia. Alem dísso em escóla numerosa, o melhór meio de ter os meninos quietos e assental-os a escrever (CAMPAGNE, 1886, p. 880).

O quadro-negro é um dos instrumentos desta relação.

A cor do quadro-negro sujeitava-se à necessidade de visibilidade expressa no contraste entre o material que escreve e a superfície sobre a qual se escreve, condições experimentadas em usos anteriores: nas mesas de areia, na lousa individual, nas cartas. Em qualquer que fosse o suporte de escrita, haveria que se garantir visibilidade suficiente para a definição dos caracteres: letras ou numerais. Patentear a criação deste dispositivo é reconhecer fusão de formas, exercícios de inventividade, propriedades das práticas engendradas pela cultura escolar, reveladas no itinerário da ardósia/pedra/lousa/quadro-negro. E o giz?

Em francês, a palavra crayon, "lápis", é derivada de craie, "calcário", "giz" (LAROUSSE, 1869, p. 458). O giz foi o primeiro lápis, e o canivete (fino, para apontar a pena; ordinário, para o lápis de pedra), o primeiro apontador ou aparador. A origem etimológica da palavra "giz" pode ser atribuída às substâncias calcárias de sua composição, o sulfato de cálcio (gesso), gypsos (CAMPAGNE, 1886, p. 313-314). Em inglês, chalk, uma referência à sua matéria-prima por excelência, a cal (óxido de cálcio). Sabe-se de seu uso desde o período paleolítico, quando era usado em desenhos ou debuxos. É classificado pela mineralogia como carbonato ou sulfato de cal que pode ser pulverizado e que se emprega em diversos usos industriais. De matéria terrosa, é muito macio; sua densidade é igual a 2,31. Frágil, "deixa-se apagar com a unha". "É encontrado em bancos espessos ou massas contínuas" e sua extração é "uma tarefa delicada" (LAROUSSE, 1869, p. 438).

O giz de uso escolar é empréstimo do giz usado pelos artistas da Renascença. O giz utilizado nas escolas paulistas do século XIX era adquirido em libras (medida de peso equivalente a $0,458 \mathrm{~kg}-\mathrm{FIC}^{6}$, [19--], p. 160) ou maços,

${ }^{6}$ FIC: sigla para identificar os Frères de l'Instruction Chrétienne, isto é, os Frades das Escolas Cristãs, congregação religiosa fundada na França por Jean Baptiste de La Salle em 1720. Esses frades foram os responsáveis pela produção de coleção de livros didáticos identificada pela sigla FIC. Os livros Elementos de Arithmetica e Elementos de Geometria fazem parte da coleção FIC e foram traduzidos no Brasil pelo professor Eugênio de Barros Raja Gabaglia no final do século XIX (VALENTE, 1999, p. 176-177). Este estudo emprega parte da obra Elementos de Arithmetica ([18--]). 
assim como na Espanha eram adquiridas as "barras de gesso" (RICO, 1997, p. 99). O preparo do giz que é usado na escola requer aquecimento da cal e mistura com argila.

Nas escolas do início do século XIX, era usado o lápis de ardósia:

Os lápis de ardósia ou lápis cinza são destinados a escrever ou desenhar sobre a ardósia; freqüentemente, compõem-se de fragmentos de ardósia um pouco mais macia. A grafite também é utilizada como lápis sem ser encerrada num invólucro de madeira; ganha então a forma de pequenos cilindros que se colocam em porta-lápis metálicos (LAROUSSE, 1869, p. 458).

Chamado "rude lápis de ardósia", o lápis de pedra também era chamado "pena de lousa", "pena de pedra", "giz de pedra" e "grafite de pedra". Tinha inconvenientes:

As professoras de escrita o criticavam por tornar a escrita rígida e seca, não permitindo formar os traços redondos e finos das letras e forçando o aluno a se apoiar, a pesar sobre o lápis. Este lápis, por sua vez é muito duro e muito quebradiço, tornando-se logo um fragmento sobre o qual os dedos se irritam (BROUARD, 1911a, p. 109).

Os inconvenientes eram minimizados com a colocação do lápis de ardósia em porta-lápis, espécie de anel feito de cobre, invólucro cilíndrico de madeira ou caneta de latão. Mais tarde, "a rude penna de lousa foi substituida por um lapis de massa menos dura, que não faz a mão pesada, e que se póde metter numa lapiseira ordinaria" (ARDÓSIA, 1886). O novo lápis era chamado "lápis da Alemanha" e sua maciez proporcionava uma grande vantagem sobre o lápis de ardósia.

Canivetes diferentes eram usados para aparar penas ou para desbastar lápis de pedra e garantir melhores traços sobre a ardósia. Nas escolas paulistas, eram usados dois tipos de canivete, os "ordinários" e os "finos". Os ordinários eram usados para "desbastar" os lápis de pedra; os finos destinavam-se ao preparo das penas, tarefa de responsabilidade do professor quando se tratava de alunos menores. $\mathrm{O}$ canivete era utensílio que se prestava a usos marginais de escrita. 
A mesa é de carvalho maciço e socado, aí a gente grava o nome a canivete [...] Gravar seu nome na madeira de sua mesa é severamente punido. Mas as mesas existem há tanto tempo, talvez desde a invenção da escola, que gerações de nomes se entrelaçam, profundamente entalhados ou apenas esboçados, uns muito artisticamente ornamentados de volutas ou trabalhados em estilo gótico arcaico, e a malandragem consiste em infiltrar seu nome secreto entre os outros de tal maneira que só um iniciado consiga reconhecê-lo. Um decifrador paciente pode até reconstituir frases inteiras assim disfarçadas: "Nabu é um panaca" ("Nabu", diminutivo de "Nabucodonosor", é evidentemente o apelido do professor), ou então "Dona Casagrande ocupa todo o terreno" (a sra. Casagrande é mesmo um pouco rechonchuda) (DOISNEAU; CAVANNA, 1999, p. 12-14).

A escrita do giz sobre a lousa é apagada com a esponja, adquirida também em libras pelas escolas paulistas do século XIX.

A zoologia classifica a esponja (do latim spongia) como um corpo do grupo dos espongiários, que pode ser classificado como animal ou vegetal. Este corpo é empregado para diversos usos, dada a sua propriedade de absorver e reter líquidos e também de se deixar espremer com ligeira pressão. Exemplos disto são as esponjas de banho e cozinha, cujo uso doméstico é corrente na França desde o século XVI. Para ser usada, a esponja é submetida a um processo de limpeza e branqueamento (LAROUSSE, 1933, p. 228-229). É a propriedade de absorção da esponja que é empregada no uso escolar: em lugar de umidade, absorve o pó de giz com o qual se escreve sobre a ardósia.

No final do primeiro terço do século XIX, os alunos ingleses e norte-americanos usavam o slate eraser ou apagador de ardósia, espécie de tampão esponjoso apoiado em metal. Alunos austríacos e alemães utilizavam um apagador "em pele delicadamente montado na forma de um pincel pequeno" (BROUARD, 1911a, p. 111). O luxo dos utensílios de escrita empregados por alunos austríacos, norte-americanos, ingleses ou alemães não era preocupação das autoridades francesas, diz Brouard (1911a, p. 111). Às crianças francesas era assegurado o necessário: ardósia, lápis e um pano de limpeza para apagar os riscos do giz, evitando que a criança não se servisse da manga da camisa ou dos próprios dedos.

A rápida difusão do emprego escolar da ardósia ocorreu "por motivos, não mais econômicos, mas essencialmente pedagógicos", em países "que não são os últimos do ponto de vista da instrução popular, o uso das ardósias, em lugar de se restringir, é generalizado" (BROUARD, 1911a, p. 110). Na Inglaterra e nos Estados Unidos, o uso escolar da ardósia não se restringia aos iniciantes. 
Usa-se [a ardósia] nas classes avançadas, assim como nas elementares, e para tipos de exercícios que não haviam sido imaginados até este momento. Assim, a ardósia substitui quase inteiramente o papel; ditados, exercícios de gramática e aritmética, de geografia e história, redações e até composições, quase tudo se faz sobre a ardósia (BROUARD, 1911a, p. 110).

A ardósia serve como "caderno de rascunho", enquanto o papel é empregado para a "caligrafia" ou para os trabalhos nos quais se deseja "conservar o traço", observa Brouard (1911a, p. 110), que destaca a maneira maravilhosa como os alunos norte-americanos e ingleses usavam a ardósia, com uma habilidade manual que não impedia a escrita correta e elegante. E Campagne (ARDÓSIA, 1886) observa:

Deve porem dizer-se que as lousas de que se servem são d'excelente qualidade, munidas de um caixilho de madeira e envernizada e muitas vezes também com pequenas capas de caotchou [do francês caoutchouc, "borracha"] para evitar o barulho, os caixilhos estão geralmente cheios de inscrições variaveis segundo a classe (alphabeto, ou modellos de caligraphia, ou figuras geometricas, ou formulas aritmeticas, etc.) (ARDÓSIA, 1886).

O curso do século XIX assiste a diferentes transformações da ardósia, em particular às tentativas de reduzir seus inconvenientes: o enquadramento de madeira, o encaixe na mesa de escrever, as ardósias artificiais produzidas em papelão e madeira; "alguns tentaram ainda gravar n'ella uma serie de traços destinados a guiarem a mão do aluno e a regularem as dimensões de inclinação da escripta" (ARDÓSIA, 1886). As transformações da ardósia e de outros materiais escolares serão preocupações expressas especialmente a partir da década de 50 do século XIX, quando acontece em Paris a primeira exposição universal que dedica uma das seções aos materiais escolares ${ }^{7}$, o que também se constitui como indício relevante do interesse comercial pelos materiais escolares em geral.

${ }^{7}$ Desde então, as questões escolares passariam a ser contempladas nas exposições universais. Em 1855, na Exposição Universal de Paris, a seção 7 da Classe 8 era destinada à questão escolar. Em 1862, na Exposição Universal de Londres (considerada a primeira), havia a Classe XXIX: Métodos e material de ensino elementar. Em 1867, na Exposição Universal de Paris, o Grupo X, Classes 89 a 95: Objetos especialmente expostos em vista de melhorar a condição física e moral da 


\section{Considerações finais}

O percurso aqui realizado incidiu sobre o exercício de identificar e sistematizar o aparecimento e algumas das transformações de certos materiais de ensino que compõem o cenário da sala de aula, sede da transmissão simultânea de ensino, dispositivo central da escola moderna. O destaque central foi dado para a lousa/quadro-negro, cujas matéria, função e combinação com outros materiais (giz, esponja, cartas, murais, dentre outros) revelariam, no seu trajeto histórico, certas especificidades inscritas no conjunto das relações e usos de ensino e de aprendizagem na escola primária do século XIX. Tais especificidades se traduziriam no arranjo espacial entre os envolvidos com o exercício de ensinar e aprender (professor e alunos), modos e métodos de organização do ensino (individual, mútuo, simultâneo), na relação de custo econômico, nas propriedades derivadas do ensino de aritmética, leitura e escrita.

\section{REFERÊNCIAS}

ARDÓSIA. In: CAMPAGNE, E. Dicionário universal de educação e ensino. Tradução de: BRANCO, Camillo Castello. Porto: Casa, 1886.

BARRA, Valdeniza Maria da. Da pedra ao pó: o itinerário da lousa na escola paulista do século XIX. Dissertação (Mestrado em Educação: História e Filosofia da Educação) - Pontifícia Universidade Católica de São Paulo, São Paulo, 2001.

BOSC, Ernest. Dictionaire d'architecture. Paris: Librairie de Firmin-Didot et Cie, 1879.

BROUARD, E. Ardoises. In: BUISSON, F. (Org.). Dictionnaire de pédagogie et instruction primaire. Paris: Librairie Hachette et Cie, 1911a. p. 109-111.

. Simultanée (Enseignement). In: BUISSON, F. (Org.). Dictionnaire de pédagogie et instruction primaire. Paris: Librairie Hachette et Cie, 1911b. p. 2787-2789.

BUISSON. F. Rapport sur l'instruction primaire à l'exposition universelle de Philadelphie. Paris: Imprimiére Nationale, 1876.

população, sendo as classes 89 e 90 ("Relatórios endereçados à S. Exc. M. o ministro de instrução pública pelos membros da comissão encarregada de examinar os trabalhos dos alunos e os modos de ensino expostos ao Ministério...”) conferências realizadas na Sorbonne para os professores primários que compareceram à mostra. Em 1873, na Exposição Universal de Viena; em 1875, na Exposição Universal da Filadélfia; em 1878, na Exposição Universal de Paris (BUISSON, 1911, p. 974-979). 
(Org.). Dictionaire de pédagogie et instruction primaire. Paris: Librairie Hachette et Cie, 1911. (1. ed.: 1874).

CAMPAGNE, E. Dicionário universal de educação e ensino. Tradução de: BRANCO, Camillo Castello. Porto: Casa, 1886.

CARDOSO, Teresa Maria R. Abrindo um novo caminho: o ensino mútuo na escola pública do Rio de Janeiro (1823-1840). In: BASTOS, M. H. C.; FARIA FILHO, L. M. de (Orgs.). A escola elementar no século XIX: o método monitorial/mútuo. Passo Fundo: Universidade de Passo Fundo, 1999. p. 95-118.

DEFODON, C. Abécédaire. In: BUISSON, F. (Org.). Dictionaire de pédagogie et instruction primaire. Paris: Librairie Hachette et Cie, 1911. p. 2-3.

DEMKÉS, A. Bell. In: BUISSON, F. (Org.). Dictionaire de pédagogie et instruction primaire. Paris: Librairie Hachette et Cie, 1911. p. 185.

DOISNEAU, R.; CAVANNA. Les doigts pleins d'encre. Paris: Hoebeke, 1999.

FARIA FILHO, L. M. de; ROSA, W. M. O ensino mútuo em Minas Gerais (1823-1840). In: FARIA FILHO, L. M.; BASTOS, M. H. C.; de (Orgs.). A escola elementar do século $X I X$ : o método monitorial/mútuo. Passo Fundo: Universidade de Passo Fundo, 1999. p. 177-196.

FARIA FILHO, L. M.; BASTOS, M. H. C.; de (Orgs.). A escola elementar do século $X I X$ : o método monitorial/mútuo. Passo Fundo: Universidade de Passo Fundo, 1999.

FERNANDES, R. A difusão do ensino mútuo em Portugal no começo do século XIX. In: BASTOS, M. H. C.; FARIA FILHO, L. M de (Orgs.). A escola elementar do século XIX: o método monitorial/mútuo. Passo Fundo: Universidade de Passo Fundo, 1999. p. 25-44.

FRÈRES DE L'INSTRUCTION CHRÉTIENNE (FIC). Elementos de arithmetica. Revisão e adaptação de: GABAGLIA, Eugenio de Barros Raja. Rio de Janeiro: Garnier, [19--].

GIOLITTO, Pierre. Abécédaire et la férule: maîtres et écoliers de Charlemagne à Jules Ferry. Paris: IMAGO, 1986. p. 224-288.

GRÉARD, O. Mutuel (enseignement). In: BUISSON, F. (Org.). Dictionaire de pédagogie et instruction primaire. Paris: Librairie Hachette et Cie, 1911. p. 1.534-1.551.

GUARALDO, F. Mobiliário escolar de São Paulo na república Velha. Tese (Doutorado) - Faculdade de Arquitetura, Universidade de São Paulo, São Paulo, 1987.

GUIÓN, J. La lectura y la escritura. In: AVANZINI, G. (Org.). La pedagogia desde el siglo XVII hasta nuestros dias. México: Fondo del Cultura Econômica, 1998. p. 251-271.

HÉBRARD, J. A escolarização dos saberes elementares na época moderna. Teoria \& Educação, Porto Alegre, n. 2, 1990. p. 65-110.

. La leçon et l'exercise - quelques réflexions sur l'histoire des pratiques de scolarisation. Paris: INRP-CNRS-Service d'histoire de l'éducation, 1995. 
HILSDORF, M. L. O ensino mútuo na província de São Paulo: primeiros apontamentos. In: BASTOS, M. H. C.; FARIA FILHO, L. M. de (Orgs.). A escola elementar do século XIX: o método monitorial/mútuo. Passo Fundo: Universidade de Passo Fundo, 1999. p. 197-216.

LANCASTER, J. Systema britanico de educação: sendo hum completo tratado de melhoramentos e invenções praticadas por José Lancaster. Tradução de: SKINNER, Guilherme. Porto: Typ. de Viuva Alvarez Ribeiro \& Filhos, 1823.

LAROUSSE, M. Pierre. Dictionnaire Universel du XIXe. siècle. Paris: Librairie Classique Larousse et Boyer, 1869. v. 3-4.

Paul Auge).

. Larousse du XXe. Siècle. Paris: Libraire Larousse, 1933. v. 6. (sous Le direction

LESAGE, P. A pedagogia nas escolas mútuas do século XIX. In: BASTOS, M. H. C.; FARIA FILHO, L. M. de (Orgs.). A escola elementar do século XIX: o método monitorial/ mútuo. Passo Fundo: Universidade Passo Fundo, 1999. p. 9-24.

MANACORDA, M. A. História da educação: da antiguidade aos nossos dias. 6. ed. Tradução de: MONACO, Gaetano Lo. São Paulo: Cortez, 1997.

RICO, Antón Costa. Mobiliario, dotación y equipamiento escolar en el siglo XIX. Historia de la educación: Revista universitária, Salamanca, n. 16, p. 91-112, 1997.

SOUZA, R. F. de. Templos de civilização: a implantação da escola primária graduada no Estado de São Paulo. (1890-1910). São Paulo: UNESP, 1998.

VALENTE, Wagner Rodrigues. Uma história da matemática escolar no Brasil (17301930). 1. ed. São Paulo: Annablume, 1999.

VIOLLET-LE-DUC, E. Dictionnaire raisonné de l'architecture française. Paris: VeA Morel \& Cie, 1876.

Texto recebido em 30 de novembro de 2012.

Texto aprovado em 12 de fevereiro de 2013. 